\title{
Flight restores fight in crickets
}

\section{Aggressiveness recovers much faster in male crickets forced to fly after a defeat.}

$\mathrm{t}$ is not fully understood what makes animals aggressive, although ancient Chinese gamblers, betting fortunes on the outcome of cricket fights, seemed to know a trick or two ${ }^{1}$. Inspired by their age-old wisdom, we found that we could restore aggressiveness in defeated crickets simply by activating their motor programme for flying. This behavioural effect on aggression highlights the impact of specific motor patterns on the operation of seemingly unrelated command centres. It may also provide an insight into the mechanisms underlying motivational processes and their evolution.

Fights between male crickets follow a

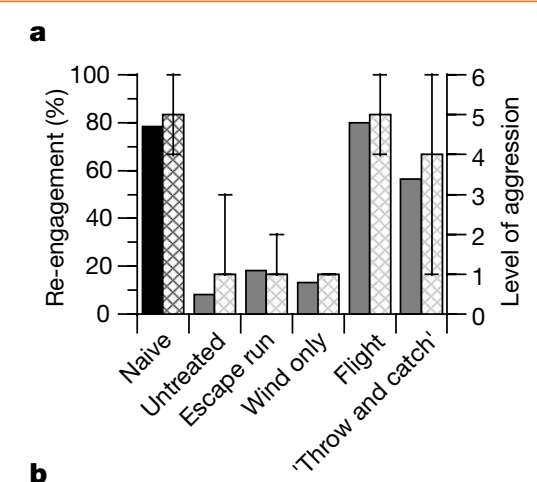

b

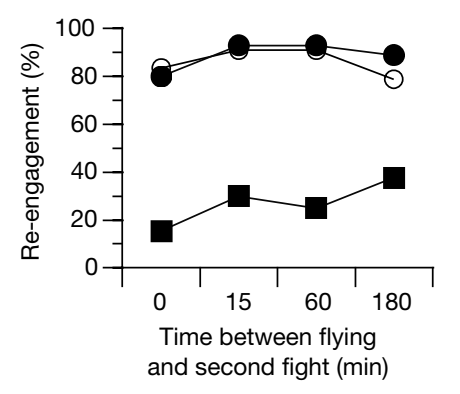

Figure 1 Behavioural depression after defeat in aggressive encounters and its alleviation by flight. Socially isolated adult male crickets, Gryllus bimaculatus, were placed in a $16 \times 9-\mathrm{cm}$ arena (details are available from the authors). Re-engagement is defined as an encounter where both animals showed overt aggression (level 4 or higher). a, Crickets do not fight immediately after a defeat, and losers do not re-engage after induced escape runs, or after suspension in a wind tunnel with contact to the ground (wind only). However, a 1-min flight immediately after losing restores fighting readiness in most losers, who show the same level of aggression as naive animals. Losers thrown into the air several times also re-engage significantly more often than untreated animals ('throw and catch'). Filled bars, re-engagement frequency; hatched bars, median level of aggression; error bars, interquartile ranges. $\mathbf{b}$, Flight induces a long-term reversal of fighting readiness. Re-engagement frequency of defeated animals is independent of the time between the first fight (immediately followed by a flight) and the second fight (circles, 10-s flight; $n=109$; filled circles, 1-min flight; $n=88$ ). The re-engagement frequency of untreated crickets is shown for comparison (squares; $n=93$ ).

NATURE | VOL $403 \mid 10$ FEBRUARY 2000 | www.nature.com stereotyped, escalating sequence. Unless one animal retreats immediately (level 1), the contestants initially fence with their antennae (level 2), and then display spread mandibles (level 3: unilateral; level 4: mutual), which later interlock (level 5) before the animals wrestle (level 6). The contest can be stopped at any level by one animal retreating. After defeat, losers avoid any more aggressive encounters (re-engagement frequency, REF, $8.2 \%, n=49$ ) Their readiness to fight recovers to the same level as naive, isolated males (REF 78.2\%, $n=179$ ) after about 24 hours $(74.4 \%, n=219)$.

As originally claimed by Chinese gamblers ${ }^{1}$, defeated crickets regain their aggressiveness after being shaken in clasped hands and thrown into the air several times (REF $56.5 \%, n=23, P<0.001, \chi^{2}$ comparison with untreated losers; Fig. 1a). It proved even more effective to induce flight behaviour in a windstream. After this, $80.0 \%$ ( $n=40, P<0.0001)$ of the losers re-engaged the previous opponent and their aggression escalated to the same level as naive animals.

Handling, sensory stimulation, and locomotion can all cause the release of amines, which affect the aggressive behaviour of arthropods ${ }^{2}$. However, the aggressiveness of subordinate crickets was not influenced by other stressful stimuli (for example, tumbling in a rotating tube), other locomotor behaviours such as 1-min episodes of wind-induced running (REF $18.2 \%, n=11$, NS), or wind stimulation when the animals had ground contact and so did not fly (REF $13.3 \%, n=15$, NS.).

The effect of flight on aggression was independent of its duration and appeared not to be transitory: a 10-s flight was as effective as a 15-min flight, and the influence of a 1-min flight was still evident hours later (Fig. 1b). The flight treatment could be

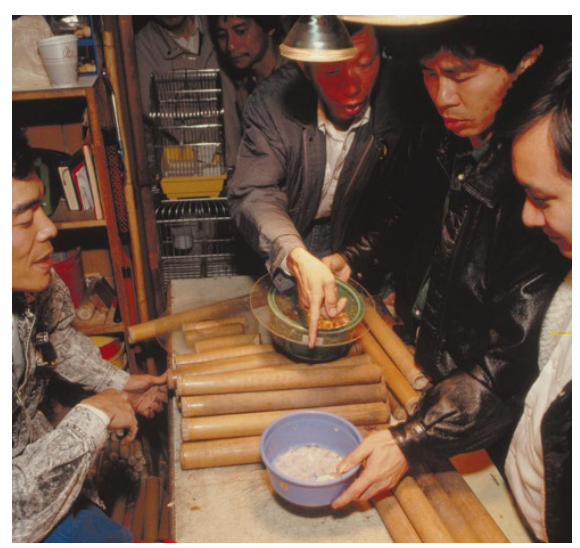

Figure 2 Chinese gamblers inspect the merchandise in a Hong Kong shop specializing in fighting crickets. repeated many times, whenever an animal lost, without losing its effectiveness.

Aggression is commanded by the brain ${ }^{3}$, and flight is produced by a thoracic centralpattern generator ${ }^{4}$. When the two connectives between these centres were severed, all animals still flew, and most showed the basic elements of aggression (antennal fencing and mandible spreading). However, flying did not restore aggression in losers with their connectives cut after defeat (REF $18.8 \%, n=16, P<0.001, \chi^{2}$ comparison with intact losers after flight). Severing only one connective had no influence on the flight effect (REF 75.0\%, $n=4$, NS). This suggests that flying initiates a nervous rather than a humoral command which acts on the brain to 'reset' the aggressiveness of subordinate crickets.

The role of plasticity in behaviour and the nervous system is widely recognized ${ }^{5,6}$, but it is rare for socially mediated behaviour to modify the nervous system of the performing animal — most examples occur relatively slowly, with long-term effects ${ }^{7-9}$. The reset of aggression by flying is the only example we know of in which activation of a specific motor pattern immediately affects an unrelated subsequent behaviour.

This phenomenon may not be unique, in which case it may stimulate some rethinking of the antidepressant effects of sleep deprivation ${ }^{10}$, and the classic ethological concept of displacement activity ${ }^{11}$. Behavioural modulation of motivational aspects of brain function may yield new insight as to how and why evolutionary adaptation has connected behaviours that were previously unrelated.

Hans A. Hofmann ${ }^{\star} \uparrow$, Paul A. Stevenson ${ }^{\star}$

*Zoologisches Institut, Universität Leipzig,

04103 Leipzig, Germany

$\dagger$ Present address: Department of Psychology,

Stanford University, Stanford,

California 94305-2130, USA

e-mail:hans@psych.stanford.edu

1. Hofmann, H. A. Biol. Zentrbl. 115, 206-213 (1996).

2. Kravitz, E. A. Science 241, 1775-1781 (1988).

3. Huber, F. Z. Tierpsychol. 12, 12-48 (1955).

4. Stevenson, P. A. \& Kutsch, W. J. Comp. Physiol. A 161, 115-129 (1987).

5. Buonomano, D. V. \& Merzenich, M. M. Annu. Rev. Neurosci. 21, 149-186 (1998).

6. Carew, T. J., Menzel, R. \& Shatz, C. J. Mechanistic Relationships Between Development and Learning: Dahlem Workshops (Wiley, Chichester, 1998).

7. Yeh, S. R., Fricke, R. A. \& Edwards, D. H. Science 271, 366-369 (1996).

8. Francis, R. C., Soma, K. \& Fernald, R. D. Proc. Natl Acad. Sci. USA 90, 7794-7798 (1993).

9. Cheng, M.-F. Anim. Behav. 43, 1035-1044 (1992).

10. Wu, J. C. \& Bunney, W. E. Am. J. Psychiatry 147, 14-21 (1990).

11. Lorenz, K. Z. The Foundations of Ethology (Springer, New York, 1981). 